\title{
On the genus Diadocidia (Diptera, Sciaroidea, Diadocidiidae) in Costa Rica
}

\author{
MATHIAS JASCHHOF ${ }^{1} \&$ CATRIN JASCHHOF $^{2}$ \\ ${ }^{\prime}$ University of Greifswald, Zoological Institute and Museum, Bachstrasse 11/12, D-17489 Greifswald, Germany. \\ E-mail: mjaschhof@yahoo.de \\ ${ }^{2}$ Jahnstrasse 7, D-17489 Greifswald.E-mail: c.jaschhof@gmx.de
}

\begin{abstract}
The genus Diadocidia Ruthe is shown for the first time to be present in Costa Rica. Three species were found: Diadocidia nigripalpis Edwards, hitherto known to occur in the south of Brazil, and two new species, hybrida and similis. While nigripalpis is confirmed to belong to the subgenus Adidocidia Laštovka \& Matile, both hybrida and similis cannot be classified on a subgeneric level, since their morphology includes features typical of both Diadocidia s. str. and Adidocidia. A key is provided to the Costa Rican species of Diadocidia.
\end{abstract}

Key words: taxonomy, morphology, Diadocidiidae, Diadocidia, new species, Neotropics

\section{Introduction}

With 20 species described, Diadocidia Ruthe is by far the largest genus of the small family Diadocidiidae (Blagoderov 2007). Laštovka and Matile (1972), in their revision of the Holarctic species, subdivided this genus into Diadocidia s. str. and Adidocidia Laštovka \& Matile. Later authors assigned most of their new species to either of these subgenera, until Papp and Ševčik (2005) introduced Taidocidia for a single new species, globosa, from Taiwan. Extant species of Diadocidia occur in all biogeographic regions except for the Afrotropics, and a fossil species is known even from Baltic amber (Blagoderov 2007).

The only Neotropical species hitherto named is Diadocidia nigripalpis Edwards from southern Brazil, which Laštovka \& Matile (1972) classified tentatively with Adidocidia. There is reference to a Diadocidia species from Chile (Freeman 1951), which was argued to be different from nigripalpis (Papavero 1977), but the single specimen known of it is not now traceable in the collections of the Natural History Museum, London (Wyatt, in litt.). The presence of Diadocidia in the northern Neotropics including Central America was hitherto undocumented, but as shown here, at least three species do occur in Costa Rica. These are, apart from nigripalpis, two unnamed species that are remarkable due to the fact that they share characters typical of both Diadocidia s. str. and Adidocidia, and thus cannot be assigned to either of these subgenera. The aims of this paper are to supplement the description of nigripalpis and introduce the new species, hybrida and similis, thereby adding to our still inadequate knowledge of the rich fungus gnat fauna of Costa Rica.

\section{Material and methods}

Specimens were picked from Malaise samples in the care of the Instituto Nacional de Biodiversidad (INBio), Santo Domingo de Heredia, Costa Rica. In 10 of 97 samples seen we found Diadocidia specimens, but only three samples yielded males. Females unaccompanied by males we did not study, but we kept them separate in 
ethanol. For study under a compound microscope we mounted the specimens in Canada balsam on glass slides, after maceration in warm potassium hydroxide $(10 \% \mathrm{KOH})$. All specimens, including types, are returned to the INBio collections. For a comparative study we obtained the type specimens, two males and one female, of Diadocidia nigripalpis from the The Natural History Museum, London (NHM). Illustrations were made using an Olympus BX50 microscope in combination with the U-DA drawing unit. Morphological terminology follows Søli (1997). Contrary to previous practice, macroseta is used instead of megaseta, as the latter is a barbarism (Gagné, in litt.).

\section{Species of Diadocidia in Costa Rica}

\section{Key to species (males)}

1 First antennal flagellomere at least four times as long as wide; gonostylus bearing subapically two large macrosetae D. nigripalpis Edwards (Fig. 1)

- First antennal flagellomere at most three times as long as wide; gonostylus lacking macrosetae ............. 2

2 First antennal flagellomere twice as long as wide; third segment of maxillary palpus thickened; apical tooth of gonostylus wide at its base D. similis sp. n. (Fig. 2B, D)

- First antennal flagellomere almost three times as long as wide; third segment of maxillary palpus not thickened; apical tooth of gonostylus narrow at its base D. hybrida sp.n. (Fig. 2A, C)

\section{Diadocidia (Adidocidia) nigripalpis Edwards, 1940}

(Fig. 1)

Characters. The first antennal flagellomere bears dorsally a few socketed setae, apart from the non-socketed setae that are somewhat shorter and cover the node entirely. The maxillary palpus is five-segmented, with the third segment elongate, a little longer and thicker than the second segment and bearing a very few short hyaline sensilla on its mesial surface. The aedeagus consists of a rod-like sclerotized apodeme that is widened and bearing numerous long trichia apically; this spatulate widening extends dorsally into a voluminous membranous portion that merges almost imperceptibly with the hypoproct (Fig. 1C). The hypoproct, discernible by the two setae on either side, is apically two-pointed and laterally strong, thereby giving the entire structure the clear contours that otherwise might be mistaken for the lateral margins of the tegmen (Figs 1A and C).

As suggested by both Laštovka and Matile (1972) and Papavero (1977), nigripalpis should be classified with Adidocidia, which is based on the following characters: the anepisternum bears five to six setae on its dorso-anterior margin; the first antennal flagellomere is four or more times longer than wide; the apical margin of ninth tergite does not bear spine-like setae; the gonostylus has a broad and deeply bifurcate apex (Fig. 1B); the anterior tarsus of female is not enlarged; and the female cercus is somewhat widened subapically (Fig. 1D).

The gonostylus in nigripalpis is diagnostic in bearing subapically two large macrosetae (Fig. 1B). Compared with the other species classified with Adidocidia, nigripalpis comes closest to the Nearctic D. borealis Coquillett (with one short macroseta subapically on the gonostylus), and D. valida Mik (with one long macroseta in some distance from the apex of gonostylus) and D. trispinosa Polevoi (with three moderately long and thin macrosetae on the mesial surface of gonostylus), both Palearctic. As regards the female terminalia, nigripalpis and borealis are similar in bearing five or so spines dorso-subapically on the cercus, which are absent in valida (the female of trispinosa is not known). These spines are larger in nigripalpis than in borealis (see Laštovka \& Matile 1972: fig. 23). Altogether, nigripalpis and borealis appear to be sister species. 


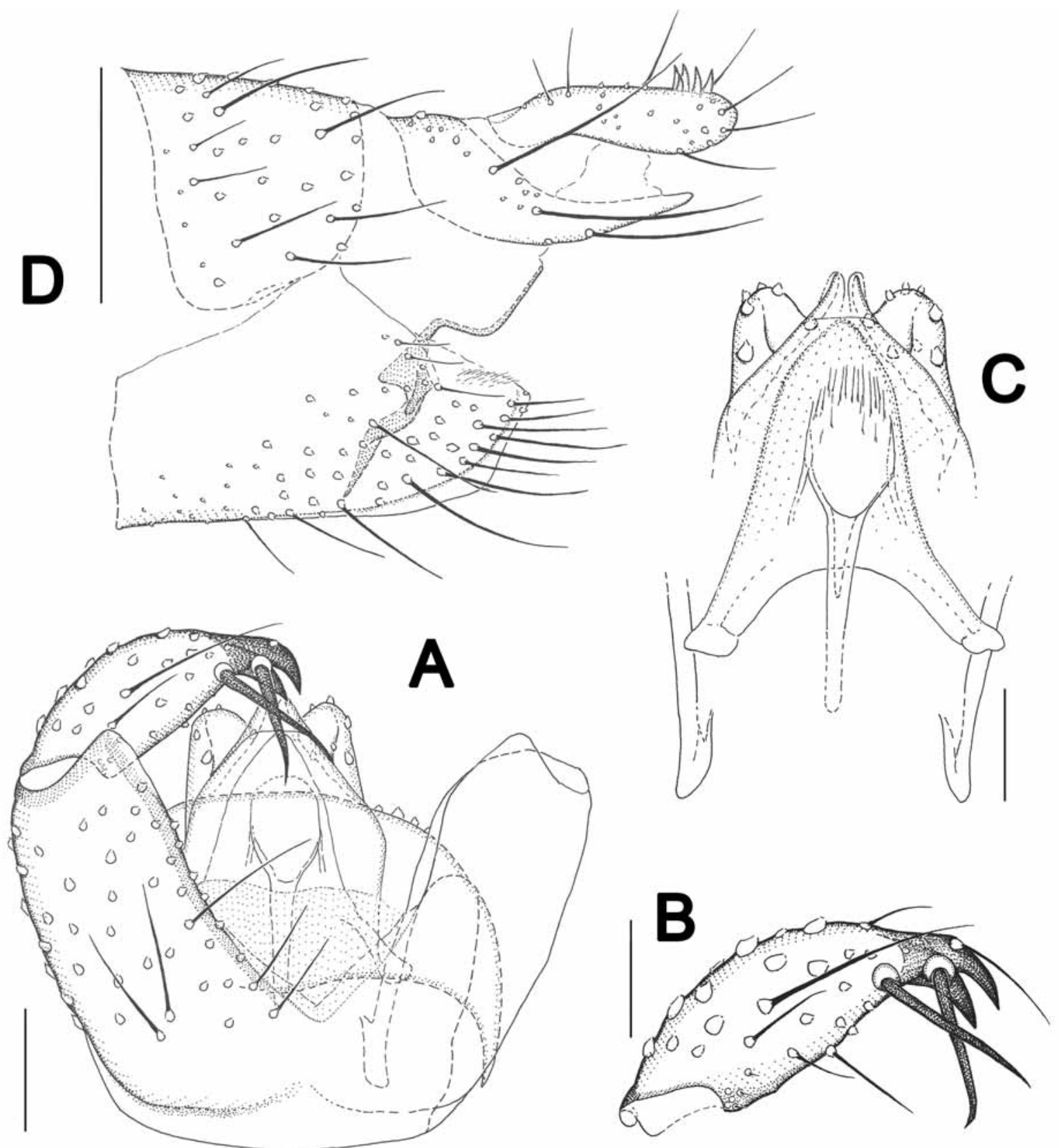

FIGURE 1. Diadocidia nigripalpis Edwards. A: Male terminalia, ventral view (specimen from Madreselva, Costa Rica). B: Gonostylus, ventral view (same specimen). C: Aedeagus, tegmen, hypoproct and cerci, ventral view (same specimen). D: Female terminalia, lateral view (specimen from La Esperanza, Costa Rica). Scale = $0.05 \mathrm{~mm}$ (B and C), 0.1 $\mathrm{mm}(\mathrm{A})$, and $0.2 \mathrm{~mm}(\mathrm{D})$.

Discussion. Specimens from Costa Rica are unquestionably conspecific with the type specimens of nigripalpis from Brazil. In two male specimens from Costa Rica with complete antennae, the first flagellomeres are four times as long as wide and thus slightly shorter than in the male syntype specimen. The balsammounted terminalia of the latter are very pale, which makes perception of structural details of the aedeagustegmen complex difficult.

Material studied. 1 male (on slide), Costa Rica, Cartago province, Finca los Lagos, Madreselva, alt. 2600 m, December 1993, by Malaise trap, M.M. Chavarria (INBio sample \#2602); 1 male, 1 female (both on slides), Cartago province, Parque Nacional Tapantí-Macizo de la Muerte, Estación La Esperanza, alt. 22002600 m, 3-22 November 2003, by Malaise trap, M. \& C. Jaschhof; 1 male (pinned, with terminalia mounted 
on a plastic sheet in Canada balsam, labelled “Type"), "Brasilien, Nova Teutonia, $27^{\circ} 11^{\prime} \mathrm{B} / 52^{\circ} 23^{\prime} \mathrm{L}$, 10.7.1938, Fritz Plaumann" (Brit. Mus. 1938-682, BMNH(E) \#253409); 1 male (pinned, with terminalia in glycerol, labelled "Syntype"), same data as previous specimen but "9.7.1939" (Brit. Mus. 1939-628, BMNH(E) \#253410); 1 female, abdomen missing (pinned, labelled "Syntype"), same data but "9.6.1939" (BMNH(E) \#253411).

\section{Diadocidia hybrida sp. $\mathbf{n}$.}

(Fig. 2A, C and E)

Description. Male. Body length $2.8-3.1 \mathrm{~mm}$. Head. Antennal flagellum bearing short non-socketed setae intermingled with a few sensory spines; longest setae as long as half flagellomere width. First flagellomere 2.3 to 2.7 times as long as wide; bearing dorsally 1-3 short socketed setae (Fig. 2A). Fourth flagellomere 1.5 times as long as wide (Fig. 2A). Maxillary palpus 5-segmented; third segment 1.8 times as long as second segment, bearing mesially a few short hyaline sensilla apart from ordinary setae elsewhere; fourth and fifth segments elongate cylindrical, fifth segment 1.6 times as long as fourth segment.

Thorax. Anepisternum with 2-3 setae in upper portion, other pleura non-setose. Legs. Antero-apical depression of fore tibia with distinct semicircular rim, bearing 20-25 non-socketed, stiff setae; apical setae arranged in line. Wing. Sc entering $\mathrm{C}$ well before level of ta. Sc-r very weak. R1 entering $\mathrm{C}$ well beyond level of M-furcation. A1 reaching wing margin. A2 absent.

Terminalia. Ninth tergite with broadly rounded apical margin, bearing setae of various sizes. Gonocoxites ventrobasally interlinked through membranous, non-setose portion, otherwise bearing setae of various sizes. Gonostylus rather stout, bearing apically strong double-tooth; tooth half as long as gonostylus body, tooth width at base 0.35 times its length (Fig. 2C). Aedeagus with rod-like apodeme, the latter apically funnellike and bearing numerous long trichia. Parameres fused to form tegmen; tegmen apically rounded, with weak contours; parameral apodemes strong. Hypoproct large, apically incised, bearing 1 large seta on either side. Cerci as large as hypoproct, bearing apically and dorsally setae of various sizes.

Female. Body length 3.0-3.1 mm. Head. First flagellomere 2.6 times as long as wide. Fourth flagellomere 1.7 times as long as wide.

Thorax. Anepisternum bearing 0-3 setae. Legs. Tarsus of fore leg not enlarged; three distal tarsomeres bearing sole of dense, stiff setae.

Terminalia. Cercus somewhat widened subapically (Fig. 2E).

Discussion. The first antennal flagellomere in hybrida is short, as is typical of the subgenus Diadocidia s. str., while the anepisternum is setose, as is typical of Adidocidia. As regards male terminalia in hybrida, the gonostylus is Diadocidia s. str.-like in having its apex slender and bifurcate for just a short distance, while the ninth tergite is Adidocidia-like in lacking spine-like setae at its apex. Female terminalia are Adidocidia-like in that the cercus is somewhat widened subapically. This adds up to a mixed constellation of features, so that hybrida cannot be classified to either Diadocidia s. str. or Adidocidia. It cannot be assigned to the subgenus Taidocidia either, because in globosa, its only species, the subcosta enters the radius, not the costa, and the gonostylus is peculiar in bearing apically a comb of thick, short macrosetae (Papp \& Ševčik 2005). Apparently, the subgeneric classification of Diadocidia needs reassessment, which should be addressed further once the extra-Holarctic fauna of diadocidiids becomes better known.

Etymology. From Latin, hybridus, hybrid, referring to the peculiar mix of characters.

Types. Holotype. Male (on slide). Costa Rica, Guanacaste province, Nandayure, Bellavista, Cerro Azul, alt. 1050 m, 1 May-19 July 2003, by Malaise trap, W. Porras \& D. Briceño (INBio sample \#74645). Paratypes. 4 males, 2 females, same data as the holotype.

Other material. 51 males, 4 females (all in ethanol), same data as the holotype. 


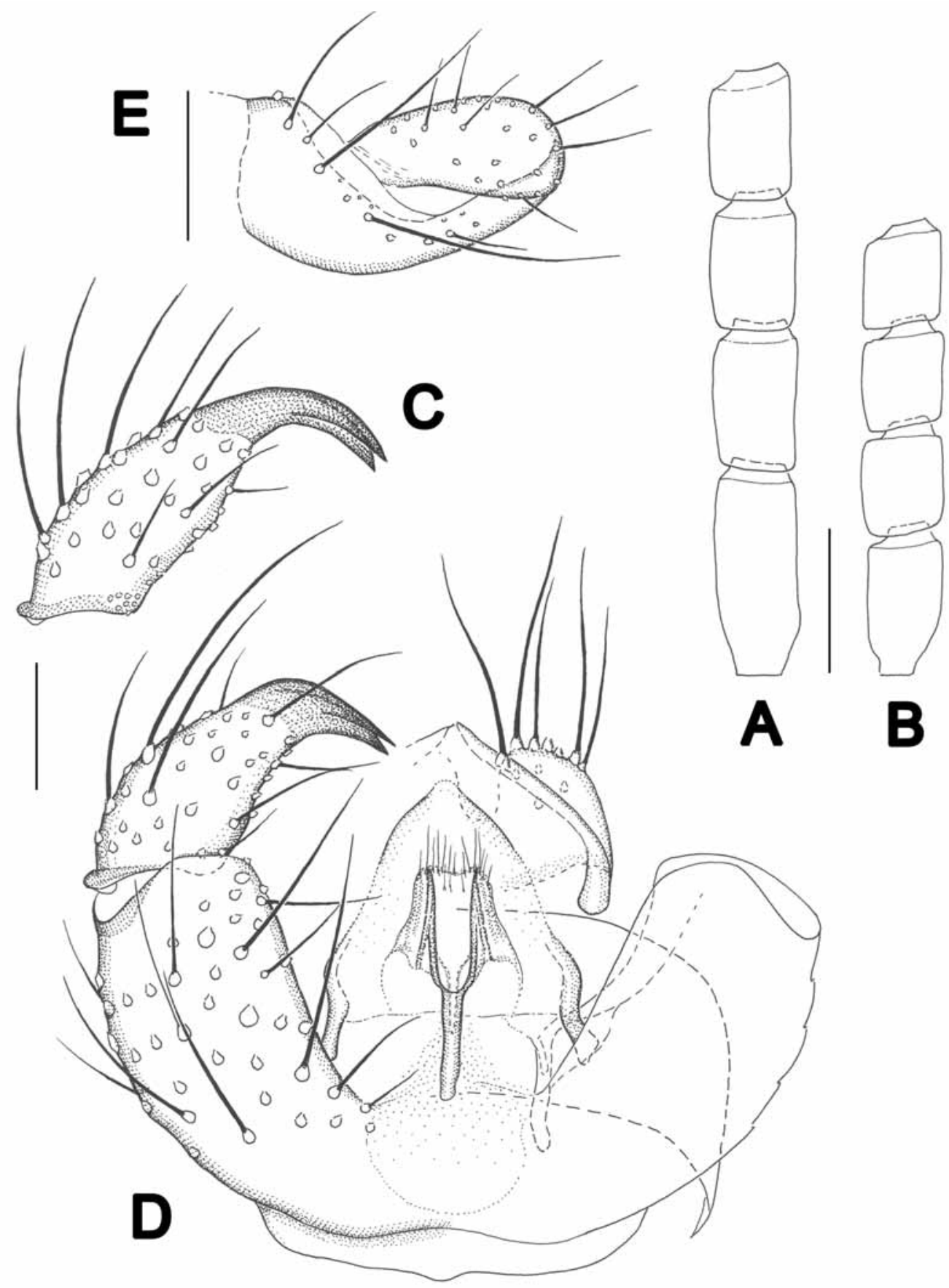

FIGURE 2. Morphology of Diadocidia spp. A: Male antennal flagellomeres 1-4, lateral view, of D. hybrida sp. n. (holotype). B: Male antennal flagellomeres 1-4, lateral view, of D. similis sp. n. (holotype). C: Gonostylus, ventral view, of D. hybrida sp. n. (holotype). D: Male terminalia, ventral view, of D. similis sp. n. (holotype). E: Apex of ovipositor, lateral view, of D. hybrida sp. n. (paratype). Scale $=0.1 \mathrm{~mm}(\mathrm{~A}, \mathrm{~B}$ and $\mathrm{E})$ and $0.05 \mathrm{~mm}(\mathrm{C}$ and D).

\section{Diadocidia similis sp. $\mathbf{n}$.}

(Fig. 2B and D)

Description. Male. Body length 2.8-3.1 mm. Head. Antennal flagellum with short non-socketed setae intermingled with a few sensory spines; longest setae as long as half flagellomere width. First flagellomere twice as long as wide (Fig. 2B). Fourth flagellomere 1.3 times as long as wide (Fig. 2B). Maxillary palpus 5-segmented; third segment thickest, stout, 1.6 times as long as second segment, bearing a very few short hyaline 
sensilla apart from ordinary setae elsewhere; fourth and fifth segments elongate cylindrical, fifth segment 1.6 times as long as fourth segment.

Thorax. Anepisternum with 4 (holotype), 8 or 12 (paratypes) setae in upper portion, other pleura non-setose. Legs. Antero-apical depression of fore tibia with distinct semicircular rim, bearing some 15 non-socketed, stiff setae scattered rather than ordered in lines. Wing. Length $2.7 \mathrm{~mm}$. Venation similar to hybrida, but Sc entering $\mathrm{C}$ shortly before level of ta.

Terminalia. Fig. 2D. Width at base of gonostylus tooth 0.4 times the length. Otherwise similar to hybrida. Female. Unknown.

Discussion. We do not assign similis to any subgenus for the same reasons as explained under hybrida. These two species are very similar and apparently closely related. Compared with hybrida, the gonostylus body in similis is somewhat broader basally and the apical tooth is thicker. The first antennal flagellomere is shorter in similis than in hybrida. The third palpus segment is thickened in similis, while it is not so in hybrida. Setae of the fore tibial anteroapical depression are scattered in similis, while they are partly arranged in a line in hybrida.

Etymology. From Latin, similis, similar, referring to the similarity to hybrida.

Types. Holotype. Male (on slide). Costa Rica, Cartago province, Parque Nacional Tapantí-Macizo de la Muerte, Estación La Esperanza, alt. 2200-2600 m, 3-22 Nov. 2003, by Malaise trap, M. \& C. Jaschhof. Paratypes. 1 male (in ethanol), same data as the holotype; 1 male (in ethanol), Puntarenas province, Parque Internacional La Amistad, Estación Altamira, Cerro Biolley, alt. 1700 m, 11 June-11 July 2001, by Malaise trap, D. Rubí (INBio sample \#64127B).

\section{Acknowledgements}

Our study of the insect collections at INBio was generously supported by INBio. We are most grateful to Manuel Zumbado for his permanent interest in our work, and to the various parataxonomists who made our field stays an enriching experience. Field work was facilitated by the staff of the Hitoy Cerere Biological Reserve and the station La Esperanza of the Tapantí-Macizo de la Muerte National Park. Nigel P. Wyatt, NHM, is thanked for arranging the loan of material. We thank Dr Raymond J. Gagné, research emeritus with the Systematic Entomology Laboratory, USDA, Natural History Museum Washington, D.C., for reading and commenting on the manuscript. Dr Vladimir A. Blagoderov, Department of Entomology, NHM, reviewed the final draft of the manuscript.

\section{References}

Blagoderov, V. (2007) Fungus Gnats Online. Available from http://www.sciaroidea.info/node/23335 (accessed 5 April 2007).

Edwards, F.W. (1940) New Neotropical Mycetophilidae IV. (Diptera). Revista de Entomologia 11(1-2), 440-465.

Freeman, P. (1951) Diptera of Patagonia \& South Chile based mainly on material in the British Museum (Natural History), Part III-Mycetophilidae. The British Museum (Natural History), London, vii+138 pp., pls I-XLIX.

Laštovka, P. \& Matile, L. (1972) Révision des Diadocidia Holarctiques [Dipt. Mycetophilidae]. Annales de la Societé entomologique de France (N. S.), 8(1), 205-223.

Papavero, N. (1977) [Chapter] 19 A, Family Diadocidiidae. In: A Catalogue of the Diptera of the Americas South of the United States. University of São Paulo, Zoological Museum, 3 pp.

Papp, L. \& Ševčik, J. (2005) New taxa of Diadocidiidae (Diptera) from the Oriental Region. Acta Zoologica Academiae Scientiarum Hungaricae, 51(4), 329-341.

Søli, G.E.E. (1997) The adult morphology of Mycetophilidae (s. str.), with a tentative phylogeny of the family (Diptera, Sciaroidea). Entomologica Scandinavica Supplement, 50, 5-55. 